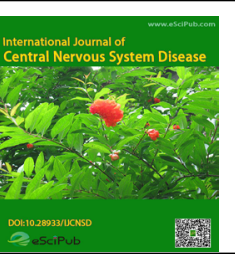

International Journal of Central Nervous System Disease

(ISSN:2637-3823)

\title{
Are pediatric patients with epilepsy at higher risk for COVID-19 Retrospective analysis from Sidra Medicine, Doha-Qatar
}

\section{Sondos Altaraqji, Rana al-Shami*, Ahlam Ahmed, Azhar Alamri, Hanem Abdullah and Patrick Tang**}

Pediatric neurology department*, pathology department** at Sidra medicine /Doha -Qatar.

\section{Abstract}

The COVID-19 pandemic, caused by Severe Acute Respiratory Syndrome Coronavirus 2 (SARS-CoV-2), spread in few months from a small focus in Wuhan (Hubei province, China) to over 28 million people worldwide, COVID-19 is often more severe in people 60+yrs or with health conditions like lung ,heart disease, diabetes or conditions that affect their immune system (1). Several countries independently adopted strict containment measures to slow the local spread of SARS-CoV-2. As other countries, widespread lockdown measures were applied in Doha -Qatar from March 17 to June 1st 2020 that restricted physical contacts, individual movements including school attendance. This reflected during the beginning of the academic year 2020-2021 by parental fear to send their children with epilepsy back to their school considering that epilepsy could be a risk factor for covid19 infection.

The prevalence of epilepsy in children ranges from 3.2 to 5.5 per 1000 , being highest in the first year of life, but matching adult rates by the end of the first decade (2). Epilepsy in children is the second greatest neurological disorder burden worldwide (3), often associated with cognitive and psychiatric comorbidities (4). These patients were not highly susceptible to COVID-19 during the pandemic, the estimate rate of infection among pediatric patient with epilepsy was around $(0.4 \%)$ for those who became sick. Meanwhile Viral infection is a risk factor for seizures in chil-

${ }^{*}$ Correspondence to Author:

Sondos Altaraqji

Sidra medicine, Doha -Qatar.

How to cite this article:

Sondos Altaraqji, Rana al-Shami, Ahlam Ahmed, Azhar Alamri, Hanem Abdullah and Patrick Tang. Are pediatric patients with epilepsy at higher risk for COVID-19 Retrospective analysis from Sidra Medicine, Doha-Qatar .International Journal of Central Nervous System Disease, 2021, 2:7.

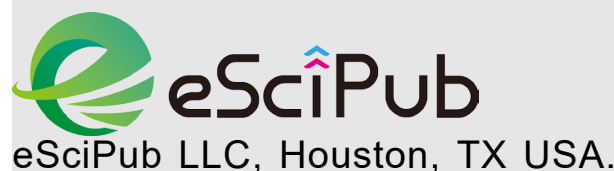
Website: http://escipub.com/ dren with certain developmental and epileptic encephalopathies (DEE) with fever sensitivity, such as Dravet Syndrome and SCN1A-related phenotypes. We aimed to assess if the COVID-19 infection affected children with epilepsy in a higher rate than other children. 


\section{Material \&Method:}

This is a retrospective analysis and chart review for pediatric patient from 0 - 18 years who presented with symptomatic covid 19 to the emergency department at Sidra Medicine during the pandemic 2020.

Their medical chart and clinical diagnosis before the infection reviewed, as a secondary gain from a research done for the clinical and the radiological manifestation of CNS involvement following respiratory viral infection in pediatric age group in Qatar

\section{Results:}

Total no of infected symptomatic covid 19 were 161,91 male and 70 female with age range from 0-18 years.

Three out of 161 with symptomatic positive covid 19 test with positive family contact had epilepsy 2 of them were in a pre-school age 2 and 3 years and the $3^{\text {rd }}$ one was 13 years.

As compared to the total 1,262 pediatric patient diagnosed with epilepsy during 2020 in pediatric neurology department at Sidra $(3 / 1,262)$, $(0.23 \%)$ infected with symptomatic covid 19.

\section{Conclusion:}

This limited study indicate that pediatric patients with epilepsy were not highly susceptible to COVID-19. Having epilepsy alone does not increase the risk of coronavirus infection.

\section{Reference:}

[1]. Marina Trivisano,a,1 Nicola Specchio, Impact of COVID-19 pandemic on pediatric patients with epilepsy - The caregiver perspective,

[2]. Epilepsy Behav. 2020 Dec; 113: 107527. Published online 2020 Nov 24 doi: 10.1016/j.yebeh.2020.107527

[3]. Camfield P., Camfield C. Incidence, prevalence and aetiology of seizures and epilepsy in children. Epileptic Disord. 2015;17(02):117-123. doi: 10.1684/epd.2015.0736. [PubMed] [CrossRef] [Google Scholar]

[4]. Murray C.J., Vos T., Lozano R., Naghavi M., Flaxman A.D., Michaud C. Disability-adjusted life years (DALYs) for 291 diseases and injuries in 21 regions, 1990-2010: a systematic analysis for the Global Burden of Disease Study 2010. Lancet. 2012;380:2197-2223. doi: 10.1016/S0140-
6736(12)61689-4. [PubMed] [CrossRef] [Google Scholar]

[5]. Tellez-Zenteno J.F., Patten S.B., Jette N., Williams J., Wiebe S. Psychiatric comorbidity in epilepsy: a population-based analysis. Epilepsia. 2007;48:2336-2344. doi: 10.1111/j.15281167.2007.01222.x. [PubMed] [CrossRef] [Google Scholar]

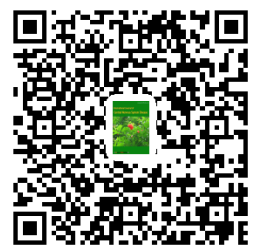

